\title{
PENGARUH ACCELERATED LEARNING CYCLE TERHADAP KEMAMPUAN KONEKSI MATEMATIS SISWA SEKOLAH DASAR
}

\author{
Muhammad Fendrik', Siti Quratul Ain ${ }^{2}$, Eva Astuti Mulyani ${ }^{1}$ \\ ${ }^{1}$ Pendidikan Guru Sekolah Dasar FKIP Universitas Riau \\ ${ }^{2}$ Pendidikan Guru Sekolah Dasar FKIP Universitas Islam Riau
}

\begin{abstract}
This research in background by the importance of good mathematical connection ability must be mastered by elementary students as one of the goals of learning mathematics. The purpose of this study, namely: 1) describe and compare between students who received learning Accelerated Learning Cycle and Conventional Learning to the ability of mathematical connections; 2) describe and compare the ability of mathematical connections and students' early mathematical abilities. This research is a quasi experimental research with experimental design in the form of group comparison. In this research plan the sample used consisted of two groups, where in each group applied different learning. The first group (experimental group) received learning Accelerated Learning Cycle, the second group (control group) applied conventional learning. The research location is in SD Negeri 136 Pekanbaru which is a medium category school. Categories are becoming the researcher's choice, because the schools in this category are mostly schools in Pekanbaru City. Based on the results of data processing, analysis, and discussion that has been presented, obtained the conclusion, namely: 1) improvement of mathematical connection ability of students who obtained learning with Accelerated Learning Cycle better than students who received conventional learning. Where the average mathematical connection ability of students who get Accelerated Learning Cycle (experimental class) is 22.78, while the average mathematical connection ability of students who obtain conventional learning (control class) is 17.03; 2) There is no significant difference in mathematical connection ability of students who obtained learning with Accelerated Learning Cycle in terms of students' mathematical ability. The significance value of equivalence test of mathematical connection data of control class students and experiment class, this is indicated by the significance value of both categories is more than 0.025 . Whereas in the initial ability of low category, the significance value less than 0.025 , so the null hypothesis is rejected, which means the mathematical connection ability of the experiment class students is better than the control class.
\end{abstract}

Keywords: accelerated learning cycle, mathematical connection ability, elementary school students

\section{PENDAHULUAN}

Matematika sebagai ilmu dasar yang diajarkan pada setiap jenjang pendidikan, sudah tidak perlu dipertanyakan lagi peranannya dalam 
perkembangan ilmu pengetahuan dan teknologi serta kehidupan sehari-hari. Mulai rakyat biasa hingga pejabat, balita hingga dewasa, ilmuwan hingga penjahat sekalipun tidak terlepas dari peran matematika. Sehingga tidak berlebihan rasanya menyepakati pendapat Carl Friedrich Gauss (Wahyudin, 2010: 2) yang mengungkapkan bahwa matematika itu sebagai ratu dari ilmu pengetahuan.

Pentingnya pendidikan matematika harus disambut dengan kepedulian dan perhatian yang serius dari berbagai pihak, terutama pihak-pihak yang berkaitan langsung dengan pelaksanaan pendidikan matematika. Depdiknas (2006: 345) menyatakan bahwa pembelajaran matematika dapat membekali siswa untuk mempunyai kemampuan berpikir logis, analitis, sistematis, kritis serta kemampuan bekerja sama. Oleh sebab itu, pelajaran matematika perlu diberikan kepada semua siswa untuk setiap jenjang pendidikan.

Pembelajaran matematika pada sekolah dasar sampai sekolah menengah dalam Kurikulum Tingkat Satuan Pendidikan (KTSP) bertujuan agar siswa memiliki seperangkat kompetensi yang harus ditunjukkan pada hasil belajar matematika (standar kompetensi), salah satunya, yaitu: memahami konsep matematika, menjelaskan keterkaitan antar konsep dan mengaplikasikan konsep atau algoritma, secara luwes, akurat, efesien dan tepat dalam pemecahan masalah (Depdiknas, 2006)

Tujuan pembelajaran matematika di atas, memperlihatkan harapan agar siswa memiliki kemampuan matematika secara khusus. Dimana diharapkan siswa dapat menjelaskan keterkaitan antar konsep. Konsep disini jelaslah merupakan konsep matematis sedangkan keterkaitan berarti hubungan atau koneksi. Sehingga, dengan kata lain, tujuan pembelajaran matematika diawali dengan harapan agar siswa memiliki kemampuan koneksi matematis yang baik.

Bukan hanya negara kita, koneksi matematis menjadi salah satu tolok ukur keberhasilan pembelajaran matematika di dunia. Seperti yang telah dirumuskan oleh Dewan Nasional Guru Matematika di Amerika Serikat, NCTM dan tercantum dalam bukunya yang berjudul 'Principles and Standard for School Mathematics' pada tahun 2000 menyatakan bahwa keterkaitan dalam matematika (connection) merupakan standar proses pembelajaran matematika. Adapun standar materi atau standar isi meliputi; bilangan dan operasinya (number and operation), aljabar 
(algebra), geometri (geometry), pengukuran (measurement), dan analisis data peluang (data analysis and probability). Ditambahkan NCTM, baik standar materi maupun standar proses tersebut secara bersama-sama merupakan keterampilan dan pemahaman dasar yang perlu dimiliki para siswa.

Koneksi matematis juga menuntut adanya berbagai kemampuan matematis yang lain. Siswa yang baik dalam konsep matematisnya tentu tidak akan kesulitan dalam menyelesaikan persoalan koneksi matematis. Begitu pula beberapa kemampuan yang lain akan menjadi penentu meningkatnya koneksi matematis siswa. Seperti yang diungkapkan oleh Coxford, Arthur F (1995):

"The mathematical processes aspect of mathematical connection includes (1) representation, (2) application, (3) problem solving, and (4) reasoning."

Pendapat ini memiliki maksud bahwa proses koneksi matematis yang dilakukan oleh siswa mencakup kemampuan matematis lainnya, diantaranya: (1) representasi, (2) aplikasi, (3) pemecahan masalah, dan (4) penalaran. Artinya, kemampuan koneksi matematis membutuhkan kemampuan pemecahan masalah. Sebaliknya, kemampuan pemecahan masalah tentunya akan membutuhkan kemampuan koneksi matematis.

Namun, dari hasil pengamatan di lapangan, tidak luput dari kesesuaian bahwa matematika itu merupakan pelajaran yang kurang disenangi oleh banyak orang. Banyak siswa yang cenderung menghindar dari pelajaran matematika. Hasil survei TIMSS pada tahun 2016 yang menempatkan Indonesia pada peringkat 44 dari 49 negara.Skor TIMMS yang diperoleh Indonesia yaitu domain pengetahuan (knowing) 395 dari skor rata-rata internasional 505, domain aplikasi (applying) sebanyak 397 dari rata-rata internasional 505 dan domain penalaran (reasoning) sebanyak 397 dari rata-rata internasional 504.

Hal ini barangkali disebabkan oleh beberapa faktor, diantaranya: siswa kita dibiasakan bertemu soal-soal rutin; siswa sering diujikan soal-soal yang sifatnya pemahaman, sedangkan untuk soal yang sifatnya mengujikan kemampuan khusus matematika jarang diberikan, sehingga ketika siswa bertemu soal yang sifatnya high order thinking, siswa kita kaget; siswa kita kurang dibiasakan mengkaitkan materi pembelajaran dengan materi yang telah diterima sebelumnya, 
pembelajaran di luar matematika, bahkan kehidupan sehari-hari; serta pembelajaran di kelas yang melulu menggunakan pembelajaran konvensional.

Pembelajaran konvensional tidaklah buruk, namun jika selalu digunakan dampaknya juga akan tidak baik bagi siswa. Siswa pastinya ingin ada sesuatu yang baru dalam setiap kegiatan menerima ilmunya. Pembelajaran konvensional menjadikan pembelajaran di kelas berpusat pada guru (teacher centered). Hal ini bertolak belakang dengan keinginan pemerintah yang tertuang pada Peraturan Pemerintah Republik Indonesia Nomor 19 Tahun 2005 Tentang Standar Nasional Pendidikan yang berbunyi:

“...Prinsip tersebut menyebabkan adanya pergeseran paradigma proses pendidikan, dari paradigma pengajaran ke paradigma pembelajaran. Paradigma pengajaran yang lebih menitikberatkan peran pendidik dalam mentransformasikan pengetahuan kepada siswanya bergeser pada paradigma pembelajaran yang memberikan peran lebih banyak kepada siswa untuk mengembangkan potensi dan kreativitas dirinya ..."

Dengan kata lain, yang dimaksud prinsip Standar Nasional Pendidikan di atas adalah perubahan dari teacher centered menuju student centered. Senada dengan hal tersebut, tabel skala keefektivitasan guru terhadap retensi siswa di bawah ini dapat menjadi pertimbangan diterapkannya student centered.

\section{Tabel 1}

Skala Keefektivitasan Guru

\begin{tabular}{|c|c|}
\hline Teknik Guru & Retensi Siswa setelah Satu Minggu \\
\hline Ceramah & $5 \%$ (dari yang mereka dengar) \\
\hline Membaca & $10 \%$ (dari yang mereka baca) \\
\hline Audio Visual & $\begin{array}{l}20 \% \text { (dari yang mereka dengar dan } \\
\text { lihat) }\end{array}$ \\
\hline Demonstrasi & $30 \%$ (dari yang mereka lihat) \\
\hline Diskusi Kelompok & $\begin{array}{l}50 \% \text { (dari yang mereka lihat, dengar, } \\
\text { dan katakan) }\end{array}$ \\
\hline Melakukan Latihan & 75\% (dari yang mereka lakukan) \\
\hline $\begin{array}{l}\text { Hubungkan dengan hal lain atau } \\
\text { menggunakannya secara langsung }\end{array}$ & $\begin{array}{l}90 \% \text { (dari yang mereka katakan dan } \\
\text { lakukan) }\end{array}$ \\
\hline
\end{tabular}

Sumber : Vernon A. Magnesen dalam Nicolls (2004)

Sehingga perlu dirancang program pengalaman belajar yang tepat agar siswa aktif dan merasakan bermaknanya pembelajaran, namun tetap gesit, bersemangat, penuh gairah, enjoy, dan nyaman (Lazim, 2018). Salah satu pembelajaran yang mendukung hal tersebut adalah Accelerated Learning Cycle. 
Prinsip belajar yang ditawarkan oleh Accelerated Learning Cycle diantaranya; belajar melibatkan seluruh pikiran dan tubuh, belajar adalah berkreasi bukan mengkonsumsi, kerjasama membantu proses belajar, pembelajaran berlangsung pada banyak tingkatan secara simultan, belajar berasal dari mengerjakan pekerjaan itu sendiri, emosi positif sangat membantu pembelajaran, serta otak menyerap informasi secara langsung dan otomatis. Dari prinsip ini, jelas harapan dari pelaksanaan pembelajaran Accelerated Learning Cycle adalah agar terjadi pembelajaran yang bermakna dan mengedepankan munculnya emosi positif siswa dimana siswa belajar dengan aktif, gesit, penuh gairah, enjoy, dan tidak tertekan.

Berdasarkan uraian di atas, peneliti tertarik untuk melakukan penelitian dengan judul "Pengaruh Accelerated Learning Cycle terhadap Kemampuan Koneksi Matematis Siswa Sekolah Dasar". Sedangkan masalah utama yang dikaji dalam penelitian ini adalah melihat pengaruh Accelerated Learning Cycle terhadap kemampuan koneksi matematis siswa sekolah dasar yang dibandingkan dengan pengaruh pembelajaran konvensional.

Penemuan akan dipandu dengan mengikuti pertanyaan berikut ini sebagai rumusan masalah penelitian: 1) Apakah siswa yang memperoleh pembelajaran Accelerated Learning Cycle memiliki kemampuan koneksi matematis yang lebih baik daripada siswa yang memperoleh pembelajaran konvensional? 2) Apakah kemampuan koneksi matematis siswa berbeda antar kemampuan awal matematis?Selanjutnya berdasarkan rumusan masalah di atas, maka tujuan penelitian ini adalah: 1) Mendeskripsikan dan membandingkan antara siswa yang memperoleh pembelajaran Accelerated Learning Cycle dan pembelajaran konvensional terhadap kemampuan koneksi matematis. 2) Mendeskripsikan dan membandingkan antara kemampuan koneksi matematis dan kemampuan awal matematis siswa.

\section{METODE PENELITIAN}

Penelitian ini merupakan penelitian kuasi eksperimen dengan desain eksperimen berupa perbandingan kelompok statik. Dalam rencana penelitian ini sampel yang digunakan terdiri dari dua kelompok, dimana pada setiap kelompok 
diterapkan pembelajaran yang berbeda. Kelompok pertama (kelompok eksperimen) mendapatkan pembelajaran AcceleratedLearning Cycle, kelompok kedua (kelompok kontrol) diterapkan pembelajaran konvensional. Desain rencana penelitian untuk eksperimen ini diilustrasikan sebagai berikut:

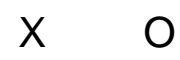

Sumber: (Russeffendi, 2005: 49)

O

Keterangan :

$\mathrm{O}$ : pemberian tes (tes kemampuan koneksi matematis siswa)

$\mathrm{X}$ : pendekatan AcceleratedLearning Cycle

Siswa tidak diberi tes awal dengan pertimbangan bahwa tes yang diberikan, yaitu tes kemampuan koneksi matematis siswa dikategorikan baru bagi siswa. Untuk mengerjakan tes ini diperlukan penguasaan materi dan strategi yang akan dipelajari siswa dalam proses pembelajaran. Oleh karena itu, pemberian tes awal dipandang kurang efektif. Pemberian tes awal juga dikhawatirkan akan mempengaruhi hasil tes akhir.

Penelitian ini terdiri dari variabel bebas, terikat, dan kontrol. Variabel bebasnya yaitu pendekatan Accelerated Learning Cycle; variabel terikatnya adalah kemampuan koneksi matematis; serta variabel kontrolnya adalah kemampuan awal matematis.Kemampuan awal matematis diperoleh dari data hasil tes mid semester siswa, dimana materi yang disajikan dalam soal mid semester merupakan materi lingkaran.

Lokasi penelitian adalah di SD Negeri 136 Pekanbaru yang merupakan sekolah dengan kategori sedang. Kategori sedang menjadi pilihan peneliti, karena sekolah pada kategori ini merupakan sekolah kebanyakan yang ada di KotaPekanbaru.

Hipotesis yang diuji adalah:

$\mathrm{H}_{0}$ : Kemampuan koneksi matematis siswa yang mendapat ALC tidak lebih baik daripada siswa yang memperoleh PK

$\mathrm{H}_{1}$ : Kemampuan koneksi matematis siswa yang mendapat ALC lebih baik daripada siswa yang memperoleh PK 
kriteria pengujian yang digunakan adalah jika nilai sig. lebih besar dari 0,05, maka hipotesis $\left(\mathrm{H}_{0}\right)$ diterima; untuk kondisi lainnya, maka $\mathrm{H}_{0}$ ditolak.

\section{HASIL DAN PEMBAHASAN PENELITIAN}

Rangkuman hasil analisis deskriptif data koneksi matematis siswa berdasarkan kategori kemampuan awal matematis disajikan pada Tabel 2 berikut.

Tabel 2

Deskripsi Data Koneksi Matematis Siswa Kedua Pembelajaran

\begin{tabular}{|c|c|c|}
\hline $\begin{array}{c}\text { Statistik } \\
\text { Deskriptif }\end{array}$ & Kontrol (PK) & Eksperimen (ALC) \\
\hline $\boldsymbol{n}$ & 31 & 32 \\
\hline$\overline{\boldsymbol{X}}$ & 17,03 & 22,78 \\
\hline $\boldsymbol{s}$ & 44,499 & 9,963 \\
\hline Min & 8 & 14 \\
\hline Max & 26 & 29 \\
\hline
\end{tabular}

Pada Tabel 2 di atas, dapat dilihat bahwa deskripsi nilai koneksi matematis kelas eksperimen lebih baik dari kelas kontrol. Selanjutnya akan diuji normalitas data dan homogenitas varians dari kemampuan koneksi matematis berdasarkan pada pembelajaran ALC (kelas eksperimen) dan PK (kelas kontrol). Hasil perhitungan uji normalitas kemampuan koneksi matematis disajikan pada Tabel 3 berikut ini:

Tabel 3

Uji Normalitas Kemampuan Koneksi Matematis

\begin{tabular}{|c|c|c|}
\hline Shapiro-Wilk & Kontrol (PK) & Eksperimen (ALC) \\
\hline Stat. & 0,806 & 0,811 \\
\hline df & 31 & 32 \\
\hline Sig. & 0,000 & 0,000 \\
\hline Keterangan $\mathrm{H}_{\mathbf{0}}$ & Tolak & Tolak \\
\hline
\end{tabular}

Dari Tabel 3 terlihat bahwa nilai signifikansi kemampuan koneksi matematis pada kedua pembelajaran kurang dari 0,05 , ini berarti hipotesis nol ditolak, yang artinya bahwa data koneksi matematis baik untuk kelas kontrol maupun kelas eksperimen tidak berdistribusi normal. Akibatnya, uji kesetaraan data koneksi matematis dilakukan dengan menggunakan uji nonparametrik, yaitu uji MannWhitney U. 
Rumusan hipotesis statistik yang diuji adalah:

$$
\begin{array}{ll}
H_{0} & : \mu_{1}=\mu_{2} \\
H_{1} & : \mu_{1} \neq \mu_{2}
\end{array}
$$

dengan

$\mu_{1} \quad=$ rata-rata koneksi matematis siswa yang mendapat pendekatan PK

$\mu_{2} \quad=$ rata-rata koneksi matematis siswa yang mendapat pendekatan ALC

kriteria pengujian yang digunakan adalah: jika p-value (sig.) lebih besar dari 0,025, maka $\mathrm{H}_{0}$ diterima; untuk kondisi lainnya $\mathrm{H}_{0}$ ditolak. Hasil uji kesetaraan data koneksi matematis siswa berdasarkan pendekatan pembelajaran disajikan pada tabel berikut.

Tabel 4.

Uji Kesetaraan Data Koneksi Matematis

\begin{tabular}{|c|c|c|c|}
\hline Mann-Whitney $\boldsymbol{U}$ & $\mathbf{Z}$ & $\begin{array}{c}\text { Sig. (2- } \\
\text { tailed) }\end{array}$ & $\mathbf{H}_{\mathbf{0}}$ \\
\hline 284,000 & $-2,963$ & 0,003 & Tolak \\
\hline
\end{tabular}

Dari tabel di atas, tampak bahwa nilai signifikansi uji Mann-Whitney $U$, kurang dari 0,025 , sehingga $\mathrm{H}_{0}$ ditolak. Dengan demikian terdapat perbedaan secara signifikan antara rata-rata kemampuan koneksi matematis kelompok siswa yang mendapat pendekatan ALC (kelas eksperimen) dan kelompok siswa yang mendapat pendekatan PK (kelas kontrol).

Untuk mengetahui pengaruh pembelajaran yang lebih baik terhadap kemampuan koneksi matematis, dapat dilakukan dengan membandingkan rerata tes kemampuan koneksi matematis siswa yang memperoleh Accelerated Learning Cycle dan pembelajaran konvensional. Dalam hal ini, berdasarkan Tabel 2, maka siswa yang memperoleh ALC (kelas eksperimen) memiliki kemampuan koneksi matematis yang lebih baik daripada pembelajaran konvensional (kelas kontrol). Dimana rata-rata kemampuan koneksi matematis siswa yang memperoleh ALC (kelas eksperimen) adalah 22,78, sedangkan rata-rata kemampuan koneksi matematis siswa yang memperoleh PK (kelas kontrol) adalah 17,03.

\section{Pengujian Hipotesis 5:}


$H_{0} \quad: \mu_{1}=\mu_{2}=\mu_{3}$ (semua sama)

$\mathrm{H}_{1} \quad: \mu_{\mathrm{i}} \neq \mu_{\mathrm{j}} ; \mathrm{i}=1,2$ dan $3 ; \mathrm{j}=1,2$, dan 3 ; untuk suatu $\mathrm{i} \neq \mathrm{j}$ (tidak semua sama) dengan

$\mu_{1} \quad=$ kemampuan koneksi matematis siswa untuk kategori rendah pada kemampuan awal matematis

$\mu_{2}=$ kemampuan koneksi matematis siswa untuk kategori sedang pada kemampuan awal matematis

$\mu_{3}=$ kemampuan koneksi matematis siswa untuk kategori tinggi pada kemampuan awal matematis

kriteria pengujian yang digunakan adalah jika nilai sig. lebih besar dari 0,05, maka hipotesis $\left(\mathrm{H}_{0}\right)$ diterima; untuk kondisi lainnya, maka $\mathrm{H}_{0}$ ditolak. Rangkuman dari hasil perhitungan uji ANOVA dua jalur data tes koneksi matematis terhadap kemampuan awal matematis disajikan pada Tabel 5.

Tabel 5

Uji ANOVA Dua Jalur Kemampuan Koneksi Matematis terhadap Kemampuan Awal Matematis

\begin{tabular}{|c|c|c|c|}
\hline Faktor & $\mathbf{F}$ & $\begin{array}{c}\text { Signifikans } \\
\mathbf{i}\end{array}$ & $\mathbf{H}_{\mathbf{0}}$ \\
\hline $\begin{array}{c}\text { Pembelajaran (P) } \\
\begin{array}{c}\text { Kemampuan Awal Matematis } \\
(\mathbf{K})\end{array}\end{array}$ & 20,636 & 0,000 & Tolak \\
\hline $\mathbf{P}^{\star} \mathbf{K}$ & 1,696 & 0,069 & Terima \\
\hline
\end{tabular}

Berdasarkan Tabel 5 terlihat bahwa nilai signifikansi uji ANOVA dua jalur untuk faktor pembelajaran adalah kurang dari 0,05. Hal ini kembali menguatkan kesimpulan dari hipotesis penelitian yang telah dipaparkan sebelumnya bahwa terdapat perbedaan pembelajaran, memberikan pengaruh yang signifikan terhadap kemampuan koneksi matematis. Dimana juga telah diungkapkan sebelumnya bahwa siswa kelas eksperimen memiliki kemampuan koneksi matematis yang lebih baik daripada siswa kelas kontrol.

Dari Tabel 5 untuk faktor kemampuan awal matematis tidak mempengaruhi kemampuan koneksi matematis siswa kedua kelompok pembelajaran. Hal ini ditandai dari nilai signifikansi yang lebih dari 0,05, sehingga hasil perhitungan untuk uji ANOVA dua jalur menerima hipotesis nol. 
Untuk mengetahui pengaruh pembelajaran terhadap kemampuan koneksi matematis berbeda berdasarkan kemampuan awal matematis, dilakukan uji perbedaan dua rerata kelas kontrol dan kelas eksperimen berdasarkan kategori kemampuan awal matematis. Hipotesis yang diuji adalah:

$\mathrm{H}_{0} \quad$ : Kemampuan koneksi matematis siswa yang mendapat ALC tidak lebih baik daripada siswa yang memperoleh PK berdasarkan kategori kemampuan awal matematis

$\mathrm{H}_{1} \quad$ : Kemampuan koneksi matematis siswa yang mendapat ALC lebih baik daripada siswa yang memperoleh PK berdasarkan kategori kemampuan awal matematis

Kriteria pengujian yang digunakan adalah jika nilai sig. lebih besar dari 0,05 , maka hipotesis $\left(\mathrm{H}_{0}\right)$ diterima; untuk kondisi lainnya, maka $\mathrm{H}_{0}$ ditolak.

Sebelum menguji hipotesis, terlebih dahulu diuji normalitas distribusi data tes kemampuan koneksi matematis baik untuk kelas eksperimen maupun kelas kontrol. Rangkuman hasil perhitungan uji normalitas distribusi data kemampuan koneksi matematis berdasarkan kemampuan awal matematis dengan uji Kolmogorov-Smirnov disajikan pada Tabel 6 berikut.

Tabel 6

Uji Normalitas Kemampuan Koneksi Matematis

\begin{tabular}{|c|c|c|c|c|c|c|}
\hline \multirow{2}{*}{$\begin{array}{c}\text { Kategori } \\
\text { KAM }\end{array}$} & \multicolumn{3}{|c|}{ Kontrol (PK) } & \multicolumn{3}{c|}{ Eksperimen (ALC) } \\
\cline { 2 - 7 } & Stat & Sig. & $\mathbf{H}_{\mathbf{0}}$ & Stat & Sig. & $\mathbf{H}_{\mathbf{0}}$ \\
\hline Tinggi & 0,420 & 0,000 & Tolak & 0,319 & 0,016 & Tolak \\
\hline Sedang & 0,266 & 0,013 & Tolak & 0,388 & 0,000 & Tolak \\
\hline Rendah & 0,336 & 0,004 & Tolak & 0,320 & 0,008 & Tolak \\
\hline
\end{tabular}

$\mathrm{H}_{0}$ : sampel berasal dari populasi berdistribusi normal

$\mathrm{H}_{1} \quad$ : sampel berasal dari populasi yang tidak berdistribusi normal

Berdasarkan Tabel 6 terlihat bahwa nilai signifikansi kemampuan koneksi matematis pada semua kategori kemampuan awal matematis kurang dari 0,05. Ini berarti bahwa data koneksi matematis baik untuk kelas kontrol maupun kelas eksperimen pada kemampuan awal matematis kategori tinggi dan sedang tidak berdistribusi normal. Akibatnya, uji kesetaraan data koneksi matematis terhadap kemampuan awal matematis dilakukan dengan menggunakan uji nonparametrik, yaitu uji Mann-Whitney $U$.

Rumusan hipotesis statistik yang diuji adalah: 


$$
\begin{array}{ll}
\mathrm{H}_{0} & : \mu_{1}=\mu_{2} \\
\mathrm{H}_{1} & : \mu_{1}<\mu_{2}
\end{array}
$$

dengan

$\mu_{1} \quad=$ rata-rata koneksi matematis yang mendapat pendekatan $\mathrm{PK}$ terhadap kemampuan awal matematis siswa

$\mu_{2} \quad=$ rata-rata koneksi matematis yang mendapat pendekatan ALC terhadap kemampuan awal matematis siswa

Kriteria pengujian yang digunakan adalah: jika $p$-value (sig.) lebih besar dari 0,025, maka $\mathrm{H}_{0}$ diterima; untuk kondisi lainnya $\mathrm{H}_{0}$ ditolak. Hasil uji kesetaraan data koneksi matematis siswa berdasarkan kemampuan awal matematis disajikan pada tabel berikut.

Tabel 7

Uji Kesetaraan Data Koneksi Matematis

\begin{tabular}{|c|c|c|c|c|}
\hline $\begin{array}{c}\text { Kategori } \\
\text { KAM }\end{array}$ & $\begin{array}{c}\text { Mann- } \\
\text { Whitney } \boldsymbol{U}\end{array}$ & $\mathbf{Z}$ & $\begin{array}{c}\text { Sig. } \\
\text { (2-tailed) }\end{array}$ & $\mathbf{H}_{\mathbf{0}}$ \\
\hline Tinggi & 26,500 & $-0,937$ & 0,349 & Terima \\
\hline Sedang & 62,500 & $-1,647$ & 0,100 & Terima \\
\hline Rendah & 7,000 & $-2,989$ & 0,003 & Tolak \\
\hline
\end{tabular}

Dari tabel di atas, tampak bahwa pada kemampuan tinggi dan sedang, nilai signifikansi uji kesetaraan data koneksi matematis siswa kelas kontrol dan kelas eksperimen tidak berbeda secara signifikan, hal ini ditandai dengan nilai signifikiansi kedua kategori ini yang lebih dari 0,025. Sedangkan pada kemampuan awal kategori rendah, nilai signifikansinya kurang dari 0,025, sehingga hipotesis nol tertolak, yang artinya kemampuan koneksi matematis siswa kelas eksperimen lebih baik daripada kelas kontrol.

Hasil statistik deskriptif data koneksi matematis siswa kedua pembelajaran, pada Tabel 3 memperlihatkan bahwa rata-rata dan variansi kemampuan pemecahan masalah kelas eksperimen lebih baik daripada kelas kontrol. Hal ini juga menjawab hipotesis penelitian yang telah diuji kesetaraannya. Koneksi matematis siswa kelas eksperimen disebabkan oleh pendekatan Accelerated 
Learning Cycle yang memiliki fase koneksi, sehingga siswa kelas eksperimen terbiasa mendapatkan materi-materi yang dikontekstualkan kedalam kehidupan sehari-hari.

\section{SIMPULAN}

Berdasarkan hasil pengolahan data, analisis, temuan dan pembahasan yang telah disajikan sebelumnya, diperoleh simpulan, yaitu: 1) peningkatan kemampuan koneksi matematis siswa yang memperoleh pembelajaran dengan Accelerated Learning Cycle lebih baik dibanding siswa yang memperoleh pembelajaran konvensional. Dimana rata-rata kemampuan koneksi matematis siswa yang memperoleh ALC (kelas eksperimen) adalah 22,78, sedangkan rata-rata kemampuan koneksi matematis siswa yang memperoleh PK (kelas kontrol) adalah 17,03. 2) Tidak terdapat perbedaan secara signifikan kemampuan koneksi matematis siswa yang memperoleh pembelajaran dengan Accelerated Learning Cycle ditinjau dari kemampuan matematis siswa (atas, tengah dan bawah). Nilai signifikansi uji kesetaraan data koneksi matematis siswa kelas kontrol dan kelas eksperimen, hal ini ditandai dengan nilai signifikiansi kedua kategori ini yang lebih dari 0,025. Sedangkan pada kemampuan awal kategori rendah, nilai signifikansinya kurang dari 0,025 , sehingga hipotesis nol tertolak, yang artinya kemampuan koneksi matematis siswa kelas eksperimen lebih baik daripada kelas kontrol.

Adapun saran yang diberikan pada penelitian ini adalah sebaiknya guru dapat memberikan proses pembelajaran secara merata kepada setiap siswa sekolah dasar tanpa terfokus kepada siswa tertentu dalam membantu kemampuan koneksi matematis siswa. Bagi siswa sebaiknya mengikuti langkahlangkah Accelerated Learning Cyclesecara benar dan teliti dalam penyelesaian sehingga dapat menghindari kebingungan pada siswa.

\section{DAFTAR PUSTAKA}

Cottin, Adrian dan ITF Simi Benhamu. (2007). Train the Trainer in Accelerated Learning Techniques Session Number TU108. Venezuela: ASTD 2007 International Conference and Exposition. http://astd2007.astd.org/speakerhandouts.htm. (diakses 06 Desember 2011). 
Coxford, Arthur F. (1995). The Case for Connection. Journal ofConnecting Mathematics Across the Curriculum. Editor: House, P.A dan Coxford, A.F. Virginia: NCTM.

Departemen Pendidikan Nasional. (2006). Kurikulum Tingkat Satuan Pendidikan. Jakarta: Pusat Kurikulum Balitbang Depdiknas.

Fendrik, M, dkk. 2016. Analisis Kemampuan Koneksi Matematis Siswa Kelas V Sekolah Dasar. Jurnal Pendidikan Serantau, 2 (2): 173-186.

http://en.wikipedia.org/wiki/List of countries by Human Development Index. (diakses 29 Desember 2011).

Lazim, Aldriyanti, N., Alpusari. M., Hermita, N., Mahbubah, K., (2018) Utilizing Cooperative Learning Model Types Make a Match to Promote Primary Students' Achivement in Science Journal of Teaching and Learning in elementary Education (JTLEE) Vol. 1 No. 1

Kinard, K dan Mary Parker. (2007). The Accelerated Learning Cycle : Are You Ready to Learn? Am I Ready to Lead?. Proceedings: United States Conference On Teaching Statistics (USCOTS) 2007. http://www.causeweb.org/uscots/uscots07/program/files/breakout2 4.pdf. (diakses 11 Oktober 2011).

Meier, Dave. (2000). The Accelerated Learning Handbook. New York: McGraw Hill.

National Council of Teachers of Mathematics. (2000). Principles and Standards for School Mathematics.USA: NCTM.

Nichiols, Ginger. (2010). Accelerated Learning and eLearning: An Overview. IT6930-Internship in Information and Learning Technologies.

Nicolls, Martina.(2004). A Second Chance: Accelerated Learning in Iraq. Iraq: Creative Associates International, Inc.

Peraturan Pemerintah Republik Indonesia Nomor 19 Tahun 2005 Tentang Standar Nasional Pendidikan

Ruseffendi, E.T. (2005). Dasar-dasar Penelitian Pendidikan dan Bidang Noneksakta Lainnya. Bandung: Tarsito.

Suherman, Erman dkk. 2003. Strategi Pembelajaran Matematika Kontemporer. Bandung: FPMIPA UPI.

Sumarmo, U. (2010). Berpikir dan Disposisi Matematik: Apa, Mengapa, dan Bagaimana Dikembangkan pada Siswa. Bandung: FPMIPA UPI. 
JURNAL TUNJUK AJAR, Volume 1, Nomor 2, 2018

P-ISSN: 2615-062X

E-ISSN: 2622-3554

https://doi.org/10.31258/jta.v1i2.116-128

Wahyudin. (2010). Kecemasan Matematika. UPI: Monograf (tidak dipublikasikan). 